\title{
Faeco-Orally Transmitted Viral Hepatitis in African Children
}

\author{
Emmanuel E. Ekanem ${ }^{1 *}$, Joanan M. Ikobah', Henry C. Okpara²
}

'Department of paediatrics, university of calabar and university of calabar teaching hospital, calabar, nigeria.

${ }^{2}$ Department of chemical pathology, university of calabar and university of calabar teaching hospital, nigeria.

\section{Article Info}

\section{Article Notes}

Received: April 14, 2018

Accepted: May 30, 2018

\section{*Correspondence:}

Dr. Emmanuel E. Ekanem, DEPARTMENT OF

PAEDIATRICS, UNIVERSITY OF CALABAR AND

UNIVERSITY OF CALABAR TEACHING HOSPITAL,

CALABAR, NIGERIA;

Email: profekanem@gmail.com

(c) 2018 Ekanem EE. This article is distributed under the terms of the Creative Commons Attribution 4.0 International License.

\section{Keywords}

Hepatitis A

Hepatitis E

Children

Africa

Water supply

Vaccines

\section{ABSTRACT}

The faeco-orally transmitted hepatotropic viruses - hepatitis A and hepatitis E viruses- are endemic in Africa. While transmission has reduced remarkably in Europe and North America in the past decades, it has remained unchanged in Africa with hepatitis A prevalence remaining at above $50 \%$ and hepatitis $\mathrm{E}$ more than $7 \%$. Much of this transmission occurs during childhood with the important drivers/predictors being poor water supply, poor sewage disposal facilities, low socioeconomic class, crowding, and poor social conditions arising from conflict. Initial clinical features in children are difficult to distinguish from malaria which is also endemic in the region. Commercially available ELISA kits present the best option for laboratory diagnosis of both viruses in Africa. While effective vaccines suitable for the African situation have been developed recently, improved water supply and sanitation are sine qua non for the prevention of transmission of both viruses among African children. Interventional studies are needed in the region.

\section{Introduction}

Viral hepatitis is a global public health problem with significant contribution to morbidity and mortality. ${ }^{1}$ Thefaeco-orally transmitted viruses-hepatitis $\mathrm{A}$ and $\mathrm{E}$ are endemic in many developing countries where, unlike their developed counterparts, environmental and socio-economic conditions favour nearly universal exposure in early childhood. ${ }^{2,3}$ Recent changes in the epidemiology of both viruses and the availability of effective vaccines have rekindled interest in them. ${ }^{4}$ This review examines the epidemiology, morbidity and modalities of prevention of hepatitis A and E viruses in African children.

\section{Methods}

A systematic literature search was carried out in Google Scholar and PubMed using combinations of the search terms related to viral hepatitis A and E and African children. These were arranged in sections for coherence and clarity.

\section{Epidemiology}

Perhaps one of the earliest epidemiological surveys of HAV in Africa was in 1982 where Ayoola ${ }^{5}$ recorded a prevalence of $82 \%$ in 250 persons aged 5 to 70 years. The prevalence among those aged 5-19 years was $42.5 \%{ }^{5}$ This study was however hospital based. In 1985 Prince et $\mathrm{al}^{6}$ in Liberia surveyed children aged 0-4 years and found prevalence rates of $\mathrm{HAV}$ ranging from $2.5 \%$ at $0-6$ months of age to $70 \%$ at 3-4 years, with annual incidence rate of $45 \%$ between 1 and 4 years of life.

In 2007 Salamaet $\mathrm{al}^{7}$ reported the prevalence of HAV among 
children from different socio-economic backgrounds in Cairo, Egypt. They studied 426 children from low socioeconomic background aged 3 to 18 years and found a prevalence of $90 \%, 142$ children of same age range from higher socio-economic background and found a prevalence of $50 \%$. Ikobah et $\mathrm{al}^{8}$ in 2015 studied 406 children aged 1-18 years in southern Nigerian communities. Of these $224(55.2 \%)$ were positive for anti-HAV antibody with the older children being more infected. Similar to the Cairo study, ${ }^{7}$ low social class and older age were predictors of infection, with $13 \%$ risk of infection for every one year increase in age. ${ }^{8}$ Thus it can be argued that, unlike in Europe and North America, there has been no significant decrease in HAV infection in African children in the past several decades.

Hepatitis E epidemiology is similar to that of hepatitis $\mathrm{A}$, and is endemic in many developing countries of Africa. ${ }^{9}$ Hodges $^{10}$ in Sierra Leone reported a prevalence of $8 \%$ among primary school children in 1998.Martinson et al ${ }^{11}$ studied children aged 6-18 years in rural Ghana in 1999 and recorded a prevalence rate of $\mathrm{HEV}$ infection of $4.4 \%$, the lower rate probably reflecting the lower population density in Ghana. Adesina et al $^{12}$ studied 20 children, including sick children, in rural Southwest Nigeria in 2009 and reported $22.2 \%$ of them infected. In 2015,Ekanemet $\mathrm{al}^{13}$ reported a survey of 406 children aged 1-18 years in a rural southern Nigerian community. A seroprevalence rate of $7.7 \%$ was found with the older children significantly more infected. These rates can be contrasted with the $0.9 \%$ reported in children in Turkey in 2002. ${ }^{14}$ During an epidemic in Bangui, Central African Republic, Goumba et al $^{15}$ reported a prevalence of $78 \%$. In the middle of 2017 , an outbreak was reported in Ngala, north eastern Nigeria involving 25 pregnant women with a case- fatality rate of $8 \%$. It is not clear from the report if children were involved. ${ }^{16}$ Thus similar to HAV, HEV infection has not declined in Africa over the past several decades.

\section{Drivers and Predictors of HAV and HEV transmission in African Children}

HAV is transmitted through the faeco-oral route due to faecal contamination of drinking water or food, person to person contact, transfusion of infected blood products, vertical (materno-foetal) transmission. ${ }^{17}$ Five days before clinical symptoms appear, the virus can be isolated from the faeces of the patient and stays detectable in the faeces up to two weeks after onset of jaundice. ${ }^{18}$ In children and the immunocompromised, faecal excretion of HAV can still occur up to five months. ${ }^{19}$ Communicability is highest during this period of viral shedding and this explains why poor faecal disposal is a predisposing factor to HAV infection.

Inadequate sanitation in much of Africa maintains continous transmission of HAV infections in children. ${ }^{19}$ Salama et $\mathrm{al}^{7}$ in Cairo demonstrated marked difference in the prevalence of HAV in children between the socioeconomic groups - 90 percent for the low socioeconomic group and $50 \%$ for the high. This was almost certainly due to differences in levels of sanitation and water supply. Ikobahet $\mathrm{al}^{8}$ in southern Nigeria also demonstrated marked difference in prevalence rates between the socioeconomic groups with those in the low socioeconomic group having 6.5 times increased risk of infection compared to those in the high, with a $9 \%$ increased risk with every extra member of the household ${ }^{8}$ Crowded households is a major feature of the low socioeconomic group in Africa. ${ }^{20}$ Long duration of stay in the community, probably reflecting longer exposure to risk factors and the virus, predicted the infection. ${ }^{8}$ Neither Ikobah et $\mathrm{al}^{8}$ in Nigeria, nor, Escobedo-Melendze et $\mathrm{al}^{21}$ in Mexico were able to demonstrate significant association between type of waste disposal and water source, and HAV infection in children. This may be because these amenities were almost universally poor in the populations they studied. Vancelik et $\mathrm{al}^{22}$ has argued that analysis of drinking water may be more important than just stating the source. Vertical transmission of HAV is generally believed to be rare because the IgG crosses the placenta ${ }^{19}$ and does not seem to have been reported in Africa.

$\mathrm{HEV}$ is transmitted through the faeco - oral route mainly by the consumption of water contaminated with sewage in developing countries. ${ }^{23}$ In Africa bore hole, wells and surface water are the main sources of water for drinking, with notoriously poor quality particularly in relation to microbial counts. ${ }^{24,25}$ In developed countries HEV RNA has been detected in human sewage occasionally. ${ }^{24}$ This may well be more common in Africa.

In the southern Nigeria study by Ekanem et $\mathrm{al}^{13}$ $58.1 \%$ of the subjects positive for anti-HEV antibody used borehole as source of drinking water and $38.7 \%$ got their drinking water from a stream. Twenty-six (83.9\%) of the subjects positive for HEV used pit latrine, and four (12.9\%) used water closet. Though these differences were not statistically significant, the social amenities were generally poor.Most of the seropositives (96.8\%) belonged to the lower social class. ${ }^{13}$ In the recent outbreak reported in north eastern Nigeria, the main drivers of outbreak were identified as volatile security situation that resulted in intense movement of populations and overcrowded official and unofficial internally displaced persons camps arising from conflicts. In these camps there is overstretching of the already weak systems with limited access to water, sanitation, hygiene, and health services. ${ }^{16} \mathrm{With}$ no screening of blood for HAV and HEV before transfusion on the continent, the potential for blood transfusion related transmission remains for both viruses. ${ }^{17,26}$ 
Clinical features and challenges of diagnosing HAV and HEV infections in African children

While HAV infection is mainly sub-clinical in the developed world with more than $90 \%$ of children less than 5 years having inapparent infection, ${ }^{19}$ it is more severe in environments characterized by poverty and poor sanitation..$^{19,27}$ Clinical features are characterized by an acute febrile illness with an abrupt onset of anorexia, nausea, malaise, abdominal pain, diarrhoea, vomiting, passage of dark coloured urine and jaundice. The icteric phase generally develops within 10 days of the initial symptom. Typical duration of illness is 7 to 14 days. Regional lymph nodes and the spleen may be enlarged. Extra-hepatic manifestations of hepatitis A are unusual but do occur. The bone marrow may be moderately hypoplastic and aplastic anaemia has been reported. ${ }^{28}$ All these features may occur in malaria ${ }^{28}$ and the other infections endemic in Africa, making clinical diagnosis in the early stage difficult except in the context of an outbreak.

The clinical features of hepatitis $\mathrm{E}$ infection range from asymptomatic infection to mild hepatitis to sub-acute liver failure. The incubation period of HEV infection ranges from two to ten weeks with an average of 40 days. ${ }^{24}$ The symptoms are indistinguishable from other forms of viral hepatitis. The symptoms may include anorexia, malaise,abdominal pain in older children, nausea, fever, vomiting, myalgia, pruritus, headaches, arthralgia, and rash. Once jaundice appears the prodromal symptoms subside. Once again, all these features may occur in malaria. ${ }^{28}$ Some patients may not present with symptoms at all. ${ }^{24}$ In a hospital based study of patients in the United Kingdom with unexplained hepatitis, 40 patients with autochthonous hepatitis E were identified, of whom $75 \%$ were icteric. The presentation of HEV in individuals infected in developed countries seems to be similar to that from endemic regions. However the mortality rate in developing countries is higher, ranging from 8 to $11 \% .{ }^{9}$ Acute infections resolve in one to four weeks. Some patients develop a more prolonged clinical illness with cholestatic hepatitis. ${ }^{24} \mathrm{HEV}$ is not known to progress to chronicity or cirrhosis in immunocompetent patients. ${ }^{24}$

Of the laboratory tests available for the detection of HEV and HAV infections, ranging from antibodydetection using enzyme Linked Immunoassay (ELISA) and radioimmunoassay, ${ }^{27}$ to cell culture, HAV and HEV RNA detection in blood or stool, ${ }^{29}$ the use of commercially available ELISA test kits ${ }^{30,31}$ would be the most feasible in Africa for reasons of cost and ease of performance, not requiring highly technical manpower. These serological kits exhibit very high sensitivity and specificity. ${ }^{30,31}$

\section{Treatment}

There is no specific antiviral therapy for treatment of hepatitis $\mathrm{A}$, therefore prevention is the most effective approach against the disease. ${ }^{19}$ Supportive treatment is recommended and this consists of intravenous hydration as needed, anti-pruritic agents and fat-soluble vitamins for the prolonged cholestatic form of disease. Serial monitoring for signs of acute liver failure and early referral to a transplantation center can be life-saving. ${ }^{19,27}$ Unfortunately livertransplantation services are practically unavailable in sub-Saharan Africa, except for South Africa, emphasizing the need for prevention. Treatment of HEV infection is supportive as well. Preliminary studies in cell cultures suggest ribavirin and interferon alpha may inhibit hepatitis E replication. ${ }^{32}$ In practical terms, prevention and supportive management are the only options in subSaharan Africa, except South Africa.

\section{WATER FIRST, AND VACCINES}

Almost all HAV infections are spread by the faeco-oral route. Good personal hygiene, high quality standards for public water supplies and proper disposal of sanitary waste have resulted in a low prevalence of HAV infections in many well developed societies. ${ }^{23}$ These cannot be said to be widely available in Africa. It is interesting to note that previous history of diarrhoea, which has similar route of transmission and risk factors as HAV and HEV, was recently demonstrated to be a predictor of HAV infection in southern Nigeria. ${ }^{8}$ Improved water situation, personal and food hygiene would therefore serve not only for HAV and HEV prevention, but also help control many other conditions endemic in Africa.

The availability of two inactivated, highly immunogenic and safe HAV vaccines has had a major impact on the prevention of HAV infection. Both vaccines are approved for children from one year of age. They are administered intramuscularly in a two dose schedule with the second dose given 6-12 months after the first dose. Seroconversion rates in children exceed ninety percent after an initial dose and approaches hundred percent after the second dose. ${ }^{34}$ A study done in Chile showed that routine vaccination of toddlers reduced the rates of symptomatic hepatitis A and associated mortality. ${ }^{33}$ The two-dose vaccine schedule evaluated in the study was less expensive than the disease related costs in the absence of vaccination from the sixth year of its implementation. ${ }^{33}$ This should suit the situation in Africa which in many ways is similar to South America. In Israel, Australia and Spain, routine childhood vaccination also resulted in marked reduction in the incidence of acute HAV infection..$^{34-36}$ The prospective duration of antibody persistence after vaccination is estimated to be at least 20 years. ${ }^{23,37}$ Several HEV vaccines are under development, including a vaccine that has now completed a phase II randomized placebo-controlled trial in Nepal. The vaccine was shown to have an efficacy of $95.5 \%$ in 898 Nepalese male army recruits over a 2-3 year period, with placebo 
group becoming infected with HEV during the study. ${ }^{40}$ This vaccine was shown to be highly effective and safe but it is yet to be commercialized as it is believed not to be profitable. ${ }^{39}$ The second HEV vaccine, which is a genotype 1 recombinant HEV Capsid protein vaccine developed in China, has a vaccine efficacy of $100 \%$ after three doses in a phase III trial involving 11,165 Chinese participants. ${ }^{41}$ HEV vaccine has been licensed for use in China. A study by Zhang et $\mathrm{a}^{42}$ as a follow-up on the cohort originally studied showed a long lasting immunity.Studies are underway to prove the safety of the vaccine in infected pregnant women in the third trimester, to protect unborn children from the high rates of spontaneous abortion and stillbirths. ${ }^{43}$

\section{Conclusion}

Transmission of hepatitis A and hepatitis E viruses among African children has remained intense over the past few decades. Persistent poverty, poor water supply, crowding, and movement of populations due to conflicts leading to increase numbers of internally displaced persons, are the main drivers of transmission. The clinical features are difficult to distinguish from uncomplicated malaria and many other infections endemic on the continent. Improved water supply and vaccination are the main options for prevention. Interventional studies with focus on water are needed in Africa to help convince governments and other organisations. The efficacy and feasibility of the emerging vaccines in the African environment need to be studied.

\section{Conflict of interests}

No conflict of interest.

\section{Funding}

This work received no funding from any funding agency in the public commercial or not-for-profit sectors.

\section{References}

1. Holinger FB, Ticehurst J. Hepatitis A virus. In: Virology, $2^{\text {nd }}$ ed. BN Fields (ed) Raven Press, New York. 1990; 631-667.

2. Arankalle VA, Chadha MS, Clitambar SD, et al. Changing epidemiology of hepatitis A and hepatitis E in urban and rural India (1982 -98). J Viral Hepat. 2001; 4: 293-303.

3. Chau TN , Lai ST, Leung VK, et al. Epidemiology and Clinical features of sporadic hepatitis E as compared with hepatitis A. Am J Gastroenterol. 2006; 101:292- 296

4. Hadler SC. Global impact of hepatitis A virus infection: changing patterns. In: Viral Hepatitis and Liver Disease, $3^{\text {rd }}$ ed. FB Hollinger (ed) Williams \& Wilkins, Baltimore. 1991; 14-20.

5. Ayoola EA. Antibody to Hepatitis A virus in Healthy Nigerians. J Nat Med Ass. 1982; 74: 465-468.

6. Prince AM, Brotman B, Richardson L, et al. Incidence of hepatitis A virus (HAV) infection in rural Liberia. J Med Virol. 1985; 15: 421-8.

7. Salama II, Samy SM, Shaaban FA, et al. Seroprevalence of hepatitis A among children of different socioeconomic status in Cairo. East Mediterr Health J. 2007; 13: 1256- 1264.

8. Ikobah JM, Okpara HC, Ekanem EE, et al. Seroprevalence and predictors of hepatitis A infection in Nigerian children. Pan Afr Med Journal. 2015; 20: 120 doi: 10.11604/pamj.2015.20.120.5501.

9. Dalton HR, Bendall R, Ijaz S, et al. Hepatitis E: an emerging infection in developed countries. Lancet. 2008; 8:698-709.

10. Hodges M, Sanders E, Aitken C. Seroprevalence of hepatitis markers; HAV, HCV and HEV amongst primary school children in Freetown, Sierra Leone. West Afr J Med. 1998; 17: 36-37.

11. Martinson FE, Marfo VY, Degraaf J. Hepatitis E virus seroprevalence in children living in rural Ghana. West Afr J Med. 18: 76-79.

12. Adesina OA, Japhet MO, Donbraye E, et al. Anti hepatitis E virus antibodies in sick and healthy individuals in Ekiti State Nigeria. Afr J Microbiol Res. 2009; 3: 533-536.

13. Ekanem E, Ikobah J, Okpara H, et al. Seroprevalence and predictors of hepatitis E infection in Nigerian children. J Infect DevCtries. 2015; 9: 1220-1225 doi: $10.3855 /$ jidc. 6736 .

14. Colak D, Ogunc D, Gunseren F, et al. Seroprevalence of antibodies to hepatitis $\mathrm{A}$ and $\mathrm{E}$ viruses in paediatric age groups in Turkey. ActaMicrobiolImmunolHungarica. 2002; 49: 93- 97.

15. Goumba AI, Konamna X, Komas NP. Clinical and epidemiological aspects of a hepatitis E outbreak in Bangui, Central African Republic. BMC Infectious Diseases. 2011, 93. http://www.biomedcentral. com/1471-2334/11/93(15 Mar, 2018,date last accessed).

16. WHO. Emergency Preparedness and Response. Acute Hepatitis E Nigeria. WHO. Disease Outbreak News. 12 July, 2017.

17. Naoumon NV. Hepatitis A and E. Medicine. 2007; 35: 35-38.

18. Dienstag JL, Feinston SM, Kapikian AZ, et al. Faecal shedding of hepatitis A antigen. Lancet. 1975; 1: 765-767.

19. WHO. Hepatitis A. Geneva .World Health Organization 2000 WHO/ CDS/SCR/ EDC/2000. 7(15 Mar 2018,date last accessed).

20. Parby JI, Lozano GN, Mason D, et al. 000388925. 2015. Stocktaking of the housing sector in sub-Saharan Africa: Challenges and opportunities (vol.2): main report (English). Washington, D.C. World Bank Group. http//documents.worldbank.org/curated/ en/551311468194953133/main-report.

21. Escobedo- Melendez G, Fierro NA, Roman S, et al. Prevalence of hepatitis A, B and C Serological markers in children from western Mexico. Ann Hepatol. 2012; 11: 194-201.

22. Vancelik S, Guraksin A. Hepatitis A seroepidemilogy in Eastern Turkey. East Afr Med Journal. 2006; 83: 86-90.

23. Pischke S, Wedmeyer H. Hepatitis E: an underestimated problem? In: Mauss S, Berg T, Rockstroh J, Sarrazin C, Wedmeyer H ( ${ }^{3 r d}$ Ed). Hepatology a clinical textbook. Flying Publishers, Germany 2012: 5564.

24. Nwidu LL, Oveh B, Okoriye T, et al. Assessment of the water quality and prevalence of water borne disease in Amassome, Niger Delta, Nigeria. Afr J Biotech. 2008; 7: 2993 - 2997.

25. Oludare A, Sikiru S. Microbilogical, Physiochamecal and Mineral quality of bore-hole water in Ijebu Land, Ogun State, Nigeria. Lut J ScAdu Tech. 2012; 2: 23 - 30.

26. Vishwanathan R, Sidhu AS. Infectious Hepatitis in Delhi (1955-1956), A Critical Study: Epidemiology. Indian J Med Res. 1957; 45: 49-58.

27. Kyle Jensen M, Balistreri WF. Viral Hepatitis. In: Kliegman RM, Stantru BF, St Gerne JW, Schor NF. Ed. Nelson textbook of Paediatrics, $20^{\text {th }}$ Ed. Philadelphia: WB saunders Company, 2016: 1942 -1953.

28. Ogala WN, Orogade AA, Mokuolu OA. Malaria. In: Azubuike JC, Nkanginieme KEO (editors). Paediatrics and Child Health in a Tropical Region. ( $3^{\text {rd }}$ ed). Lagos, Educational Printing and Publishing, 2016; p525-35. 
29. Arankalle VA, Ticehurst J, Sreenivasan MA. Aetiological association of a virus -like particle with enterically transmitted non-A, non-B hepatitis. Lancet. 1988; 1: 550- 554.

30. Koff RS. Clinicalmanifestations and diagnosis of hepatitis A virus infection. Vaccine. 1992; 10: 15- 17.

31. Chen HY,LuY,Howard T.Comparison ofa newImmunochromatographic Test to Enzyme-Linked Immunosorbent Assay for Rapid Detection of Immunoglobulin M Antibodies to Hepatitis E Virus in Human Sera. ClinDiagn Lab Immunol. 2005; 12: 593-598.

32. Pischke S, Wedemeyer H. Hepatitis A. In: Mauss S, Berg T, Rockstroh J, etal.Eds.Hepatology 2012 ( $3^{\text {rd }}$ ed). Germany: DruckhausSud. 2012: $27-31$.

33. Quezada A, Baron- Papillon F, Condeville L, et al. Universal vaccination of children against hepatitis A in chile: a cost- effectiveness study. Rev PanamSaludPublica. 2008; 23: 303- 312.

34. Maiwald H. Long- term persistence of anti- HAV antibodies following active immunization with hepatitis A vaccine. Vaccine. 1997; 15: 346 $-348$.

35. Dagan R, Leventhal A, Anis E, et al. Incidence of hepatitis A in Israel following universal immunization of toddlers. JAMA. 2005; 294: 202 210
36. Lopalco PL, Salleras L, Barbuti S, et al. Hepatitis A and B in children and adolescents- What can we learn from Puglia (Italy) and Catalonia (Spain). Vaccine. 2000;19: 470-474

37. Hanna JN, Hills SL, Humphreys JL. Impact of hepatitis A vaccination of Indigenous children on notifications of hepatitis A in north Queensland. Med J Aust. 2004; 181: 482-485

38. Shrestha MP, Scott RM, Joshi DM, et al. Safety and Efficacy of a Recombinant Hepatitis E Vaccine. N Engl J Med. 2007; 356: 895 - 903.

39. Ogholikhan S, Schwarz KB. Hepatitis Vaccines. Vaccines (Basel). 2006 Mar; 4(1): 6

40. Zhang J, Liu CB, Li RC, et al. Randomized Controlled Phase II Clinical Trial of a Bacterial Recombinant Hepatitis E Vaccine. Vaccine. 2009; 27:1869-74.

41. Tacke F, Trautwein C. Efficient Recombinant Hepatitis E Virus Vaccine: Mission Accomplished. Hepatology. 2007; 46: 941-943.

42. Zhang J, Zhang XF, Huang SJ, et al. Long-term efficacy of a hepatitis E vaccine. N Engl J Med. 2015; 372: 914-922

43. Krawazynski K. Hepatitis E Vaccine - Ready for Prime Time. N Engl J Med. 2007; 356: 949 - 951. 